Check for updates

Cite this: RSC Adv., 2019, 9, 34888

Received 20th August 2019

Accepted 22nd October 2019

DOI: $10.1039 / c 9 r a 06526 a$

rsc.li/rsc-advances

\section{Effect of ZnO on (ferroelectric) fatigue retention and thermal stability of ferroelectric properties in lead free $\left(\mathrm{K}_{0.5} \mathrm{Na}_{0.5}\right)\left(\mathrm{Nb}_{0.7} \mathrm{Ta}_{0.3}\right) \mathrm{O}_{3}$ ceramics $\dagger$}

\begin{abstract}
Vineetha P, (D) * Roshan Jose (D) and K. Venkata Saravanan (ID
This work investigates and reports the effect of $\mathrm{ZnO}$ addition on the ferroelectric properties of $\left(\mathrm{K}_{0.5} \mathrm{Na}_{0.5}\right)\left(\mathrm{Nb}_{0.7} \mathrm{Ta}_{0.3}\right) \mathrm{O}_{3}$ (KNNT) ceramics prepared by a solid state reaction method. Though literature is abundant on the study of the effect of $\mathrm{ZnO}$ on the sinterability, microstructure and electrical properties of KNN based materials, the effect of $\mathrm{ZnO}$ on their ferroelectric properties has seldom been studied in detail, especially in KNNT. In the current study, 2, 4 and $6 \mathrm{wt} \%$ of $\mathrm{ZnO}$ was added to KNNT ceramics. The $\mathrm{XRD}$ results revealed $\mathrm{ZnO}$ addition has no effect on the crystal symmetry of KNNT. However, a $\mathrm{ZnO}$ secondary phase was found in KNNT ceramics with 4 and $6 \mathrm{wt} \% \mathrm{ZnO}$ doping. An increase in grain size was observed with increases in the concentration of $\mathrm{ZnO}$, indicating a direct dependence of grain size on the concentration of $\mathrm{ZnO}$ in the KNNT matrix. From ferroelectric studies it was observed that a lower electric field was sufficient to get maximum polarization for $\mathrm{ZnO}$ doped KNNT samples compared to that of pure KNNT ceramics. A high remnant polarization $\left(P_{\mathrm{r}}=14.0 \mu \mathrm{C} \mathrm{cm}{ }^{-2}\right)$ and lower coercive field $\left(E_{\mathrm{c}}=\right.$ $5.6 \mathrm{kV} \mathrm{cm}^{-1}$ ) was obtained for $2 \mathrm{wt} \% \mathrm{ZnO}$ doped KNNT. These samples showed the least fatigue $(0.8 \%)$ after $10^{9}$ cycles in comparison to pure (5\%), 4 wt\% $\mathrm{ZnO}$ doped (24.9\%) and 6 wt\% $\mathrm{ZnO}$ doped (30\%) KNNT ceramics. The diminution in $P_{\mathrm{s}}, P_{\mathrm{r}}$, and $E_{\mathrm{c}}$ was only $26.0 \%, 26.2 \%$ and $18.5 \%$, respectively, with an increase in measurement temperature, which indicates improved thermal stability in $2 \mathrm{wt} \% \mathrm{ZnO}$ doped KNNT. From the present study the optimum concentration of $\mathrm{ZnO}$ in KNNT is identify to be 2.0 wt\% and their improved properties in comparison to the pure KNNT ceramics are discussed in detail.
\end{abstract}

\section{Introduction}

The main characteristic of a ferroelectric material is the existence of spontaneous polarization and its reversal in an externally applied alternating electric field. ${ }^{\mathbf{1}}$ The polarization that subsists in the material even after the removal of the electric field (remnant polarization) directs the material towards use in a variety of applications. Ferroelectric fatigue grabs attention as soon as a ferroelectric material finds an application where it has to be run through a cyclic electric field. The mode (unipolar/ bipolar) as well as the strength of electric field that has to be applied in a device depends particularly on the specific application. In order to resist stress that would be developed by reorientation of dipoles, actuators have to be run in unipolar mode whereas in memory applications the device has to be operated in an alternating electric field. ${ }^{2}$ In any application the enduring performance of the component is an essential requirement and in the case of a ferroelectric material the main

Department of Physics, School of Basic and Applied Sciences, Central University of Tamil Nadu, Thiruvarur-610005, India. E-mail: vineethasdi@gmail.com; Tel: +91-9387124294

$\dagger$ Electronic supplementary information (ESI) available. See DOI: 10.1039/c9ra06526a drawback is fatigue. Fatigue is the reduction in remnant polarization under cyclic polarization reversals. Researchers are more interested bipolar fatigue studies and this is probably due to the potential applications of ferroelectric materials in nonvolatile memory devices, where each cell is driven by bipolar pulses. $^{3}$ Defects that come from aliovalent doping or the impurities from the raw materials are the source of fatigue. ${ }^{4,5} \mathrm{An}$ internal electric field that has been generated by the charged defects will counteract to the external applied electric field and which results in reduced macroscopic polarization. In a donor doped (ions are substituted by ions of higher valence) material negatively charged defects and in an acceptor doped (ions are substituted by ions of lower valence) material positively charged defects like oxygen vacancies will be created to maintain the overall charge neutrality. ${ }^{6}$ Thus acceptor doping will leads to an increase in oxygen vacancy. The addition of $\mathrm{ZnO}$ has shown donor behavior in $\mathrm{KNN}$ based material. ${ }^{7}$ However it is also possible that the $\mathrm{Zn}^{2+}(0.74 \AA)$ may replace the $\mathrm{Nb}^{5+}(0.64 \AA)$ creating oxygen vacancies and leaves the material with fatigue. ${ }^{8}$ Moreover a dual character of $\mathrm{ZnO}$, acceptor behavior at $0.6 \mathrm{~mol} \%$ of $\mathrm{ZnO}$ and donor behavior when $\mathrm{ZnO}$ was added to the initial mixture was also been reported. ${ }^{9}$

Lead zirconium titanate commonly known as PZT is used in most of the devices owing to its prominent ferro and 
piezoelectric properties. But lead based materials which are detrimental to both human and environment should be replaced with lead free counter parts. Recently KNN based lead free materials have got much attention due to its properties comparable to PZT. Even then the sinterability of KNN based materials were a concerning matter. The volatilization of alkaline earth elements at high temperature makes the sample less dense and defective. ${ }^{10}$ Studies have been done to improve the density of KNN based materials by adding sintering aids such as $\mathrm{CuO}, \mathrm{MnO}$ and $\mathrm{ZnO} .{ }^{11-14}$ Although there were many reports in which $\mathrm{ZnO}$ is used as a sintering aid which improves the densification of samples along with the enhancement of piezoelectricity, ${ }^{15}$ to best of our knowledge no one has reported the fatigue endurance effect of $\mathrm{ZnO}$. It has been reported that $\left(\mathrm{K}_{0.5} \mathrm{Na}_{0.5}\right)\left(\mathrm{Nb}_{1-x} \mathrm{Ta}_{x}\right) \mathrm{O}_{3}$ composition has shown good piezoelectric property $\left(205 \mathrm{pC} \mathrm{N}^{-1}\right)$ for $x=0.3 .^{16}$ But the reported value of remnant polarization for this composition was low compared to other Ta composition. ${ }^{17}$ In general, the piezoelectric coupling factor $\left(k_{\mathrm{p}}\right)$ is proportional to the remnant polarization $\left(P_{\mathrm{r}}\right) .^{18}$ So a better ferroelectric property is expected to enhance the piezoelectric property too. This study was carried out primarily to investigate the effect of $\mathrm{ZnO}$ on ferroelectric properties of $\left(\mathrm{K}_{0.5} \mathrm{Na}_{0.5}\right)\left(\mathrm{Nb}_{0.7} \mathrm{Ta}_{0.3}\right) \mathrm{O}_{3}$. We expect that the replacement of A site elements with $\mathrm{Zn}$ will trim down the electric fatigue via reducing defects and in addition to that the role of $\mathrm{ZnO}$ as a sintering aid may also enhance the ferroelectric properties.

\section{Experimental}

All the samples were prepared by solid state reaction method from high pure carbonate and oxide precursors. Stoichiometric amount of potassium carbonate $\left(\mathrm{K}_{2} \mathrm{CO}_{3}, 99 \%\right.$, Merck), sodium carbonate $\left(\mathrm{Na}_{2} \mathrm{CO}_{3}, 99 \%\right.$, Merck), niobium (v) oxide $\left(\mathrm{Nb}_{2} \mathrm{O}_{5}\right.$, 99.9\%, Aldrich), and tantalum (v) oxide $\left(\mathrm{Ta}_{2} \mathrm{O}_{5}, 99 \%\right.$, Aldrich) were weighed and homogenously mixed for $24 \mathrm{~h}$ in acetone medium using a planetary ball mill. Then the homogenously mixture powders were dried in an oven and calcined. The calcined powers were attrition milled for about $2 \mathrm{~h}$. In order to obtain phase pure KNNT samples, 3 sets of samples were prepared. The first set of samples was calcined at $600^{\circ} \mathrm{C}$ for $5 \mathrm{~h}$. The XRD results, as shown in Fig. 1a indicate the presence of secondary phase. Hence, the calcination temperature was raised to $700{ }^{\circ} \mathrm{C}$ for one sample set and at the same time to another sample set, $5 \mathrm{wt} \% \mathrm{~K}_{2} \mathrm{CO}_{3}$ was added in excess, to compensate for the loss of potassium, if any, at high temperatures. This sample set was calcined at $600{ }^{\circ} \mathrm{C}$ for 5 hours. As evident from the XRD pattern (Fig. 1a), the samples calcined at $700{ }^{\circ} \mathrm{C}$ also resulted in secondary phase formation. Phase pure sample was obtained for samples with $5 \mathrm{wt} \% \mathrm{~K}_{2} \mathrm{CO}_{3}$ added in excess. This result points out that the secondary phase is due to the volatilization of potassium. The samples prepared under this condition were used for further studies.

In order to study the effect of $\mathrm{ZnO}$ addition on the properties of KNNT ceramics, $0 \mathrm{wt} \%, 2 \mathrm{wt} \%, 4 \mathrm{wt} \%$ and $6 \mathrm{wt} \%$ of $\mathrm{ZnO}$ was added to the calcined KNNT powder, hereafter called KNNT, KNNT2, KNNT4, and KNNT6, respectively. The ZnO added
KNNT samples were homogeneously mixed using an agate motor and pestle for $2 \mathrm{~h}$ and were uniaxialy pressed into pellets of $8 \mathrm{~mm}$ diameter and $\sim 1 \mathrm{~mm}$ thickness. Sintering (in air) of the pressed pellets was carried out at $1100{ }^{\circ} \mathrm{C}$ for $2 \mathrm{~h}$ in a muffle furnace for all the compositions. The addition of $\mathrm{ZnO}$ resulted in the formation of stable KNNT phase since none of ZnOdoped KNNT ceramics showed deliquescence when they were exposed to water for a long period of time.

The density of all the sintered samples was measured by Archimedes method. The crystal structure and phase assemblage was evaluated by X-ray diffraction technique (XRD, Rigaku Miniflex $600, \mathrm{Cu}-\mathrm{K} \alpha$ radiation) in the $2 \theta$ range from $20^{\circ}$ to $60^{\circ}$ with a step size of $0.02^{\circ}$. Scanning electron microscope (SEM, TESCANVEGA3) operating at an acceleration voltage of $20 \mathrm{kV}$ was used to determine the effect $\mathrm{ZnO}$ addition on the surface morphology of KNNT ceramics. Silver paste was applied on the two flat surfaces of the disc-shaped specimens and was fired at $100{ }^{\circ} \mathrm{C}$ for $10 \mathrm{~min}$, which acts as the electrodes to carryout electrical characterization. The ferroelectric properties such as the $P-E$ hysteresis loop, fatigue, temperature dependence (room temperature $-175^{\circ} \mathrm{C}$ ) of remnant polarization $\left(P_{\mathrm{r}}\right)$ were measured using a ferroelectric test system (Marine India PE Loop tracer).

\section{Results and discussions}

\subsection{X-ray diffraction (XRD)}

The XRD patterns of KNNT, KNNT powder calcined at $700^{\circ} \mathrm{C}$ for $5 \mathrm{~h}$ and $5 \mathrm{wt} \%$ potassium added KNNT calcined at $600^{\circ} \mathrm{C}$ for $5 \mathrm{~h}$ are shown in Fig. 1a. Presence secondary phase was observed in KNNT powder calcined at $600{ }^{\circ} \mathrm{C}$ and $700{ }^{\circ} \mathrm{C}$ for $5 \mathrm{~h}$. When an additional amount of potassium was added, phase pure samples were obtained. This result points out that the secondary phase was due to the volatilization of potassium. The XRD pattern of KNNT0, KNNT2, KNNT4 and KNNT6 ceramic samples sintered at $1100{ }^{\circ} \mathrm{C}$ for $2 \mathrm{~h}$ is shown in Fig. 1b. It is clear that all the samples exhibit perovskite monoclinic structure (JCPDS 77-0038). At lower concentrations of $\mathrm{ZnO}$ i.e., up to $2 \mathrm{wt} \%$, the intensity of $\mathrm{ZnO}$ peaks are very small, however, when the concentration of $\mathrm{ZnO}$ exceeded $2 \mathrm{wt} \%$, the diffraction peaks corresponding to $\mathrm{ZnO}$ become more intense indicating that the solubility of ZnO is limited in the KNNT matrix and the excess $\mathrm{ZnO}$ is unable to diffuse into the KNNT matrix. Similar observations have been reported in $\mathrm{ZnO}$ doped KNN ceramics elsewhere..$^{19}$ Rietveld refinement of diffraction data was done using Full Prof software and lattice parameters obtained are tabulated in Table 1. Six coefficient polynomial functions were used for background correction, Pseudo-Voiget function was used to model the peak profile and 'Profile Matching with constant scale factor' structural model was used for the refinement. The results are in good agreement with the literatures. ${ }^{20-22}$ The Rietveld fit along with the reliability factors $R_{\mathrm{p}}, R_{\mathrm{wp}}, \chi^{2}$ etc. for all samples are provided in ESI. $\dagger$

\subsection{SEM analysis}

SEM investigation was carried out to understand the influence of $\mathrm{ZnO}$ addition on the microstructural development, grain 
(a)

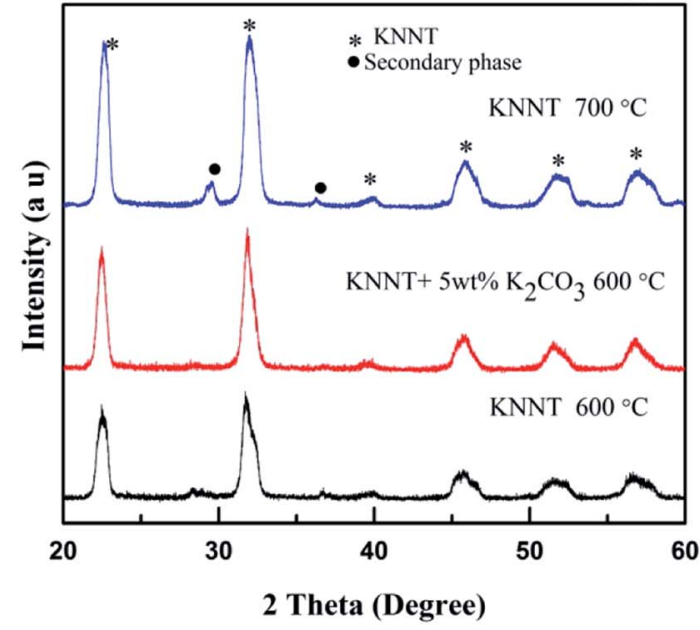

(b)

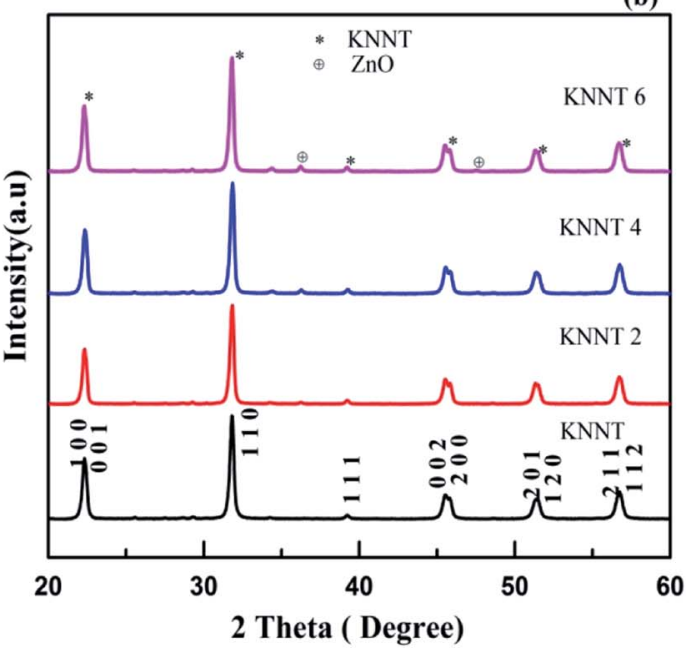

Fig. 1 XRD patterns of (a) KNNT samples (b) ZnO doped KNNT samples.

Table 1 Lattice parameters of pure and ZnO doped KNNT obtained from Rietveld refinement. The error associated with lattice parameter calculation is $\pm 0.0003 \AA$

\begin{tabular}{llllll}
\hline $\begin{array}{l}\text { Sample } \\
\text { name }\end{array}$ & $a(\AA)$ & $b(\AA)$ & $c(\AA)$ & $\beta\left(^{\circ}\right)$ & $V\left(\AA^{3}\right)$ \\
\hline KNNT0 & 3.9972 & 3.9567 & 3.97944 & 90.334 & 62.937 \\
KNNT2 & 3.9929 & 3.9538 & 3.9761 & 90.34 & 62.770 \\
KNNT4 & 3.9879 & 3.9534 & 3.9736 & 90.30 & 62.645 \\
KNNT6 & 3.9897 & 3.9556 & 3.9765 & 90.28 & 62.755
\end{tabular}

growth and densification of KNNT ceramics. Fig. 2a, shows the SEM image of the fracture surface of undoped KNNT ceramics. A porous microstructure is observed with an average grain size
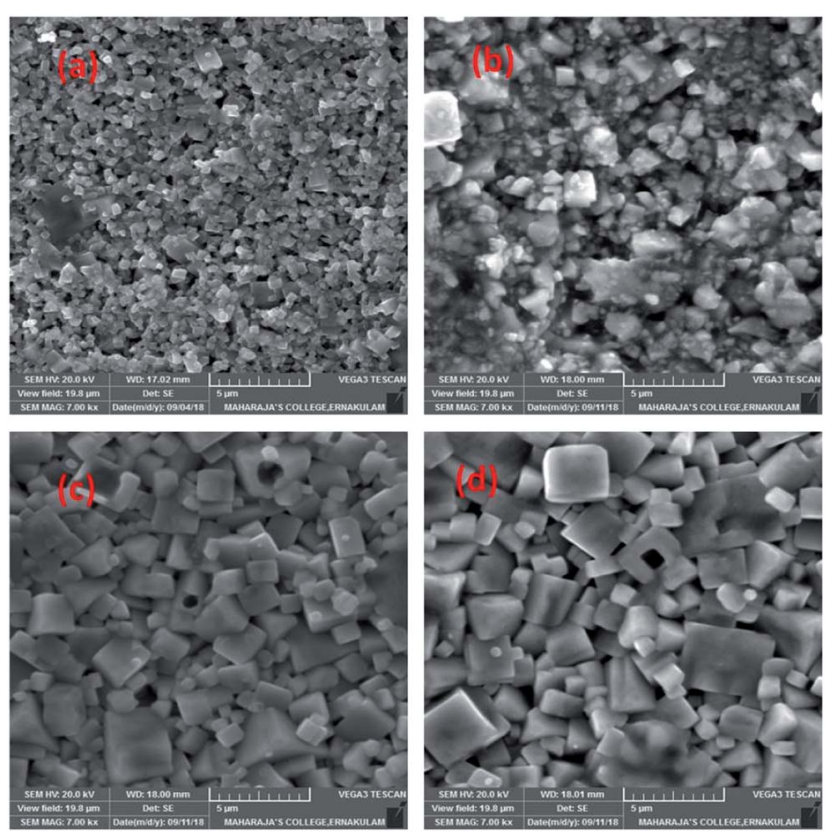

Fig. 2 SEM images of (a) KNNT (b) KNNT2 (c) KNNT4 and (d) KNNT6 ceramics. of approximately $0.31 \mu \mathrm{m}$. Fig. $2 \mathrm{~b}-\mathrm{d}$ shows the SEM micrograph of ZnO-added KNNT ceramics. All the doped samples show relatively dense microstructure. When $4 \mathrm{wt} \%$ or more $\mathrm{ZnO}$ was added, a homogeneous and dense microstructure is observed, indicating that ZnO-doping has a significant effect on the surface morphology of KNNT ceramics. It is observed that ZnO doping in KNNT results in more regular grains with increased grain size.

The average grain size and density of pure and $\mathrm{ZnO}$ added KNNT ceramic is given in Table 2. The density of KNNT2 ceramics was found to be higher than pure KNNT. However, the density decreased for higher concentrations of $\mathrm{ZnO}$. The average grain sizes of KNNT ceramics were found to increase with $\mathrm{ZnO}$ modifications. This confirms that $\mathrm{ZnO}$ addition promotes grain growth, since $\mathrm{ZnO}$ is a well-known sintering aid. ${ }^{23}$

During sintering process, the dominant mechanism for grain growth is diffusion and hence in the present case, we expect $\mathrm{ZnO}$ to exist in two forms resulting in two different distribution mechanisms; at lower concentration of $\mathrm{ZnO}$, increase in density may be attributed to the diffusion of the $\mathrm{ZnO}$ in to the KNNT host matrix forming a homogeneous mixture. Whereas, in the other hand, for higher concentrations, ZnO diffuses along the grain boundaries of KNNT, thereby enhancing the mass transport leading to increased grain

Table 2 Average grain size and density of KNNT and $\mathrm{ZnO}$ doped KNNT samples. The error associated with grain size and density calculations are $\pm 0.03 \mu \mathrm{m}$ and $\pm 0.02 \mathrm{~g} \mathrm{~cm}^{-3}$

\begin{tabular}{lll}
\hline $\begin{array}{l}\text { Sample } \\
\text { name }\end{array}$ & $\begin{array}{l}\text { Grain size } \\
(\mu \mathrm{m})\end{array}$ & $\begin{array}{l}\text { Density } \\
\left(\mathrm{g} \mathrm{cm}^{-3}\right)\end{array}$ \\
\hline KNNT0 & 0.31 & 4.01 \\
KNNT2 & 0.72 & 4.90 \\
KNNT4 & 1.16 & 4.78 \\
KNNT6 & 1.30 & 4.69
\end{tabular}


boundary diffusion, expediting grain growth rates of the KNNT ceramics. ${ }^{7,24}$ The excess $\mathrm{ZnO}$ along the grain boundary that are not diffused in to the KNNT matrix forms the secondary phase in KNNT ceramics with ZnO content of 4 and 6 wt\%. The decrease in density for KNNT ceramics with ZnO content of 4 and $6 \mathrm{wt} \%$ can also be attributed to the presence of secondary phase.

\subsection{Ferroelectric studies}

Fig. 3a-d shows the polarization versus electrical field $(P-E)$ hysteresis loops of sintered, undoped and ZnO doped KNNT ceramics measured by varying the electric field up to 30 $\mathrm{kV} \mathrm{cm}^{-1}$, at a frequency of $50 \mathrm{~Hz}$ and at ambient conditions. An increase in remnant polarization $\left(P_{\mathrm{r}}\right)$ with increase in electric field was observed for all the samples, confirming the

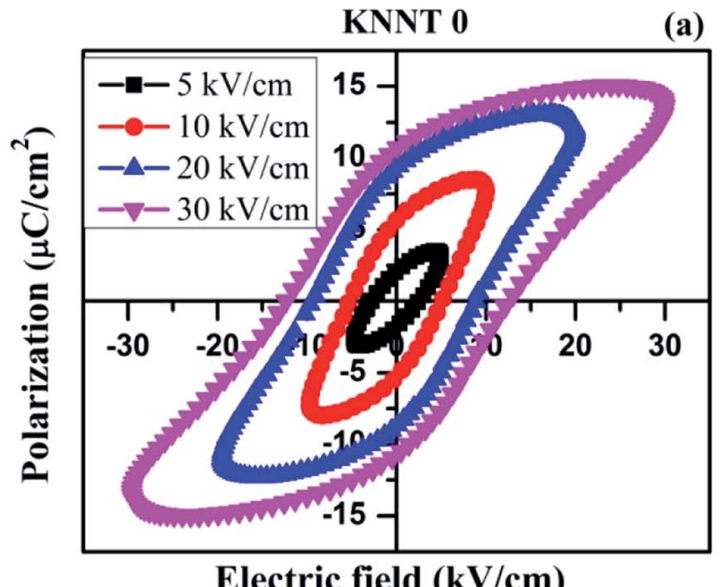

Electric field $(\mathrm{kV} / \mathrm{cm})$

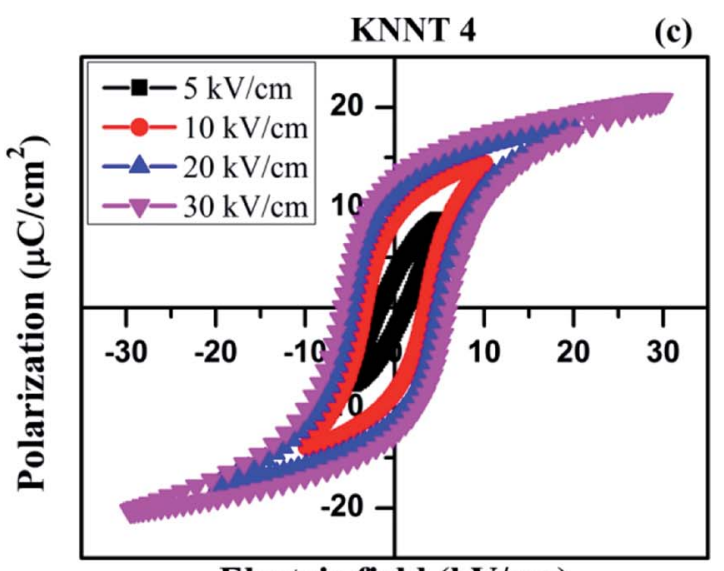

Electric field $(\mathrm{kV} / \mathrm{cm})$
KNNT 2

(b)

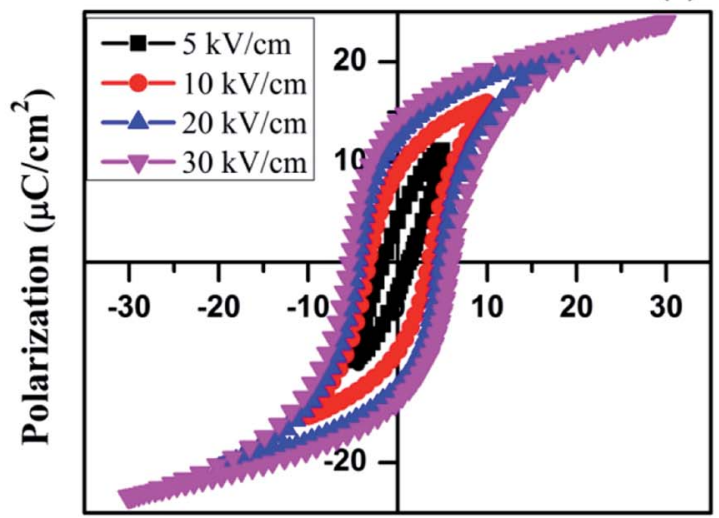

Electric field $(\mathrm{kV} / \mathrm{cm})$

KNNT 6

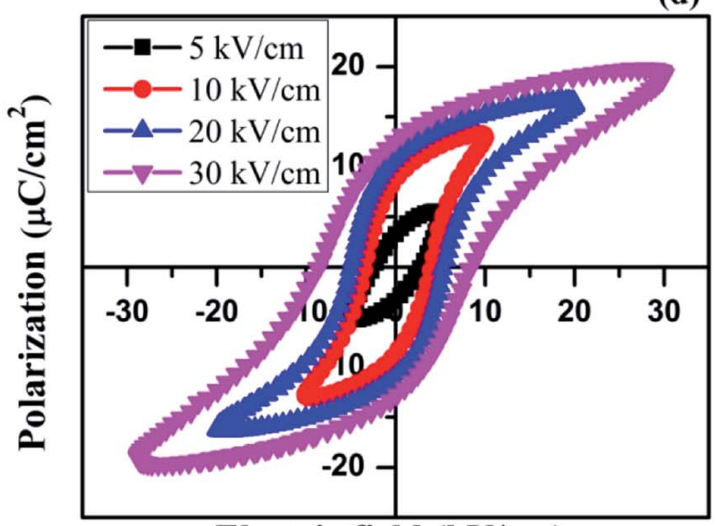

Electric field $(\mathrm{kV} / \mathrm{cm})$

(e)

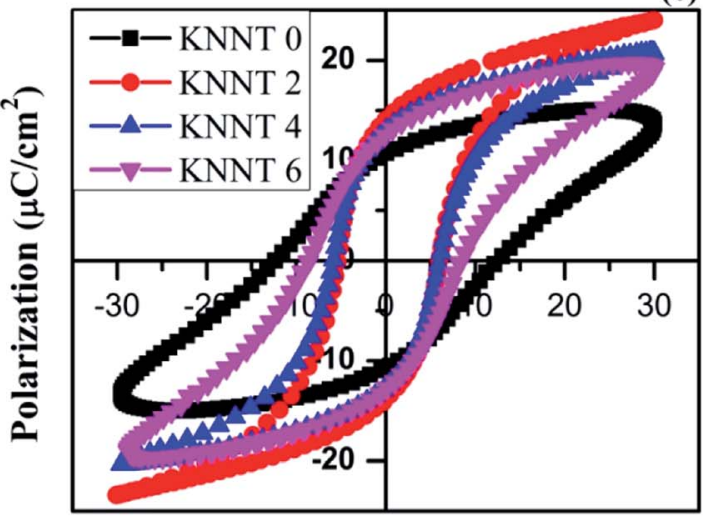

Electric field $(\mathrm{kV} / \mathrm{cm})$

Fig. 3 Shows the polarization versus electrical field $(P-E)$ hysteresis loops of (a) KNNTO (b) KNNT2 (c) KNNT4 (d) KNNT6 samples measured by varying the electric field up to $30 \mathrm{kV} \mathrm{cm}^{-1}$. (e) Represents the $P-E$ curves of all the KNNT ceramics measured at $30 \mathrm{kV} \mathrm{cm}^{-1}$. 
Table $3 P_{\mathrm{s}}, P_{\mathrm{r}}$ and $E_{\mathrm{c}}$ of undoped and $\mathrm{ZnO}$ doped KNNT at $30 \mathrm{kV} \mathrm{cm}^{-1}$

\begin{tabular}{lllc}
\hline $\begin{array}{l}\text { Sample } \\
\text { name }\end{array}$ & $P_{\mathrm{s}}\left(\mu \mathrm{C} \mathrm{cm}^{-2}\right)$ & $P_{\mathrm{r}}\left(\mu \mathrm{C} \mathrm{cm}^{-2}\right)$ & $E_{\mathrm{c}}\left(\mathrm{kV} \mathrm{cm}^{-1}\right)$ \\
\hline KNNT0 & 13.6 & 10.7 & 12.4 \\
KNNT2 & 24.0 & 14.0 & 5.6 \\
KNNT4 & 20.5 & 13.1 & 6.0 \\
KNNT6 & 19.2 & 12.8 & 8.5
\end{tabular}

ferroelectric nature of $\mathrm{ZnO}$ doped KNNT ceramics. Fig. 3e presents the $P-E$ curves of all the KNNT ceramics measured at $30 \mathrm{kV} \mathrm{cm}{ }^{-1}$. The saturation polarization $\left(P_{\mathrm{s}}\right.$, a nearly constant polarization value as $E$ increases), remnant polarization $\left(P_{\mathrm{r}}, P\right.$ at $E=0)$ and coercive field $\left(E_{\mathrm{c}}, E\right.$ at $\left.P=0\right)$ values for all the studied samples are listed in Table 3 . The variation in remnant polarization $P_{\mathrm{r}}$, and the coercive field $E_{\mathrm{c}}$ with $\mathrm{ZnO}$ concentration is shown in Fig. 4.

As observed in Fig. 4 and 3e, the undoped KNNT exhibits a leaky $P-E$ loop with $P_{\mathrm{r}}$ of $10.7 \mu \mathrm{C} \mathrm{cm}^{-2}$ and $E_{\mathrm{c}}$ of $12.4 \mathrm{kV} \mathrm{cm}^{-1}$. Similar kind of leaky loops have been reported in the case of doped and undoped $\mathrm{KNN}^{25,26}$ The leaky loop is believed to be due to charge defects, that is, cation and/or oxygen vacancies that exhibit as space charges. ${ }^{23,27}$ The space charge effect inhibits the polarization switching under a high applied field amplitude, resulting in a lower $P_{\mathrm{r}}$ and higher $E_{\mathrm{c}}$ values in undoped KNNT ceramics. The values of $P_{\mathrm{s}}$ and $P_{\mathrm{r}}$ increase with increasing $\mathrm{ZnO}$ contents and achieve the maximum values 24.0 $\mu \mathrm{C} \mathrm{cm}{ }^{-2}$ and $14.0 \mu \mathrm{C} \mathrm{cm}^{-2}$, respectively, at $2 \mathrm{wt} \%$ of $\mathrm{ZnO}$. With further increasing $\mathrm{ZnO}$ content, the decrease in the values of $P_{\mathrm{s}}$ and $P_{\mathrm{r}}$ is observed. On the other hand, the $E_{\mathrm{c}}$ value exhibits a decrease for $2 \mathrm{wt} \%$ of $\mathrm{ZnO}\left(E_{\mathrm{c}}=5.6 \mathrm{kV} \mathrm{cm}{ }^{-1}\right)$, and then increases for $\mathrm{ZnO}$ content $>2 \mathrm{wt} \%$. Hence, the optimum ferroelectric properties are found at $2 \mathrm{wt} \%$ of $\mathrm{ZnO}$ added KNNT ceramics which exhibited a well saturated, low leakage hysteresis loop. It is clear that the ferroelectric property of KNNT ceramics gets enhanced with $\mathrm{ZnO}$ addition. The enhanced properties for KNNT2 ceramics could be attributed to the role of $\mathrm{ZnO}$, that enters the KNNT matrix forming a homogeneous

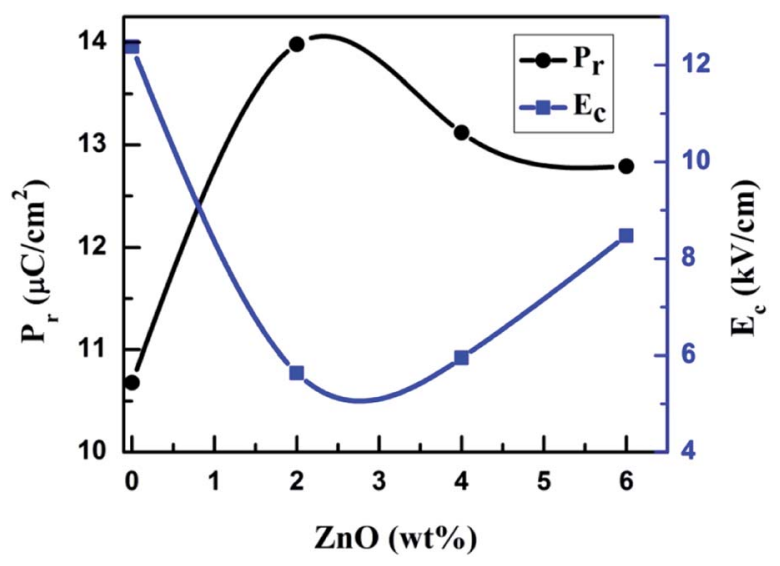

Fig. 4 Shows the variation in $P_{\mathrm{s}}, P_{\mathrm{r}}, E_{\mathrm{c}}$ with $\mathrm{ZnO}$ concentration. mixture, thereby compensating for any charge defects, resulting in reduction of conductivity in the doped ceramics as compared to undoped KNNT. ${ }^{28,29}$

With further increase in $\mathrm{ZnO}$ content (4 and $6 \mathrm{wt} \%$ ), the relative amount of KNNT to $\mathrm{ZnO}$ is reduced, resulting in the loss of $P-E$ loop shape and ferroelectric property. The ferroelectic property can adversely be affected by $\mathrm{ZnO}$ that does not enter the KNNT matrix but forms a secondary phase, as evident from the XRD and SEM results. As the KNNT to ZnO ratio is reduced the volume of KNNT having ferroelectricity favoring noncentrosymmetric, monoclinic structure, with $\mathrm{Pm}$ space group is reduced relative to the volume of hexagonal phase of $\mathrm{ZnO}$ with centrosymmetric $P 6_{3} m c$ space group. A centrosymmetric structure does not favor ferroelectricity due to zero or negligible electric dipole moment. Therefore, it is reasonable to conclude that the decrease of ferroelectricity in higher concentration of $\mathrm{ZnO}$ is due to the segregation of secondary phase of $\mathrm{ZnO}$ along the grain boundary which is confirmed from the SEM-EDX data. The EDX data of KNNT6 sample is given in ESI. $\uparrow$ It is also worth mentioning that the $\mathrm{ZnO}$ has higher conductivity, ${ }^{30}$ which can reduce the resistivity of KNNT ceramics resulting in poor ferroelectric property. The $P-E$ studies complement the XRD and SEM results.

\subsection{Fatigue retention}

The polarization fatigue in ferroelectric materials is defined as the loss of switchable polarization with respect to cyclic electric field $^{31-33}$ and it depends on various parameters including, experimental conditions such as measurement temperature, frequency, amplitude, applied electric field profile etc., material modifications such as crystal structure, microstructure, anisotropy, doping and other parameters such as leakage current, electrode type, interface layer and interface quality. However, the exact effect of the above parameters on the fatigue properties is still under debate. ${ }^{6}$ Fig. 5 shows the fatigue endurance characteristics i.e., the dependence of $P_{\mathrm{r}}$ on the number of cycles (up to $10^{9}$ ) of bipolar triangular switching pulses of the undoped and ZnO doped KNNT ceramic samples. The relative ferroelectric fatigue of the undoped KNNT ceramics

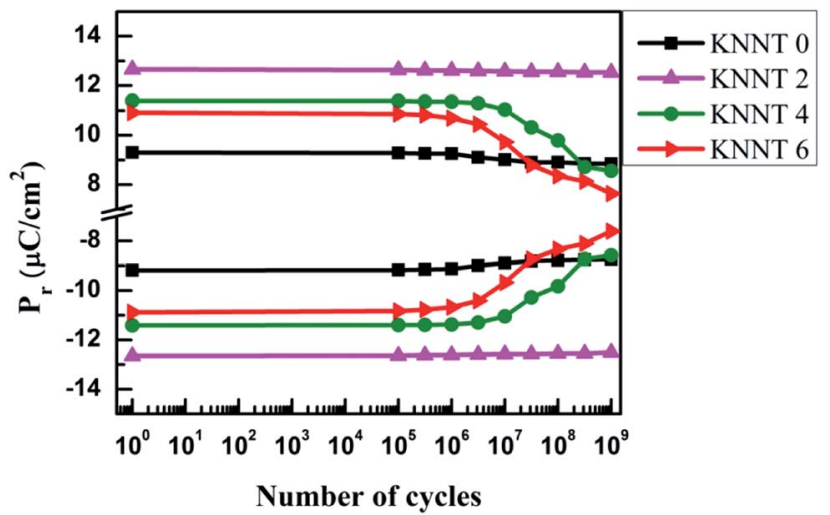

Fig. 5 Dependence of $P_{r}$ on the number of switching cycles for undoped and $\mathrm{ZnO}$ doped KNNT ceramic samples. 
were $5 \%$ which decreased to $0.8 \%$ for $2 \mathrm{wt} \%$ doped $\mathrm{ZnO}$ samples. It is to be noted that domain switching is controlled by the competition between domain pinning and depinning process $^{34}$ and fatigue is a result of charge injection and space charge accumulation that pins domain walls or impedes the nucleation and reversion of domain to permit switching. In the case of KNN based ceramics, cation vacancies are generally formed due to the evaporation of potassium or sodium while high temperature sintering and in order to maintain the charge oxygen vacancies are created.

The diffusion of oxygen vacancies present in KNNT due to volatilization of alkali metals ${ }^{35,36}$ and their aggregation lead to domain wall pinning and consequently resulting in $5 \%$ fatigue (after $10^{9}$ cycles). The fatigue is overcome to a large extent in the case of KNNT2 because the $\mathrm{Zn}^{2+}$ that enters KNNT matrix acts like a donor dopant and thus there is reduced oxygen vacancies concentration. ${ }^{37,38}$ Further increase in $\mathrm{ZnO}$ concentration yielded $24.9 \%$ fatigue in KNNT4 and $30 \%$ in KNNT6. The possible reason for such high fatigue is due to the presence of secondary, $\mathrm{ZnO}$ phase. Similar result has been reported in $\mathrm{CuO}$ doped $\left(\mathrm{Bi}_{1}\right.$ / $\left.{ }_{2} \mathrm{Na}_{1 / 2} \mathrm{TiO}_{3}\right)-\left(\mathrm{BaTiO}_{3}\right)$ ceramics. ${ }^{39}$ The secondary phase present may lead to various local regions with different polarization/ larger leakage currents which counteract the total polarization.

\subsection{Thermal stability of ferroelectric property}

In order to study the thermal stability of polarization behavior, temperature dependence of ferroelectric measurements was performed from room temperature (RT) to $175{ }^{\circ} \mathrm{C}$ on the pure KNNT and ZnO doped KNNT. Since, the macroscopic net polarization completely vanishes above the phase transition temperature $\left(T_{\mathrm{C}}\right)$, the highest temperature chosen here is far below $T_{\mathrm{C}}$. The temperature dependent $P(E)$ hysteresis loops of all the KNNT ceramics are shown in Fig. 6a-d, and the evolution of $P_{\mathrm{s}}, P_{\mathrm{r}}$, and $E_{\mathrm{c}}$ under various temperatures are plotted in Fig. 7e and f. Except for KNNT0, all other ZnO doped KNNT samples show saturated loops at room temperature. The leaky loop in KNNT0 ceramics can be as a result of charge defects arising due to cation and/or oxygen vacancies, as discussed in the earlier section. With increase in measurement temperature it is observed that the $E_{\mathrm{c}}$ increased from $8.9 \mathrm{kV} \mathrm{cm}^{-1}$ to 9.6 $\mathrm{kV} \mathrm{cm}{ }^{-1}$ by an amount of $7.3 \%$, while the $P_{\mathrm{r}}$ and $P_{\mathrm{s}}$ values reduced by $32.5 \%$ and $11.6 \%$, respectively. On addition on $\mathrm{ZnO}$, a substantial change in the thermal stability of KNNT ceramics can be observed, where excluding KNNT6, we can observe on all other sample that with increasing temperature, the $P(E)$ loops trend to become thin, accompanied by the reduced $P_{\mathrm{s}}, P_{\mathrm{r}}$ and $E_{\mathrm{c}}$.
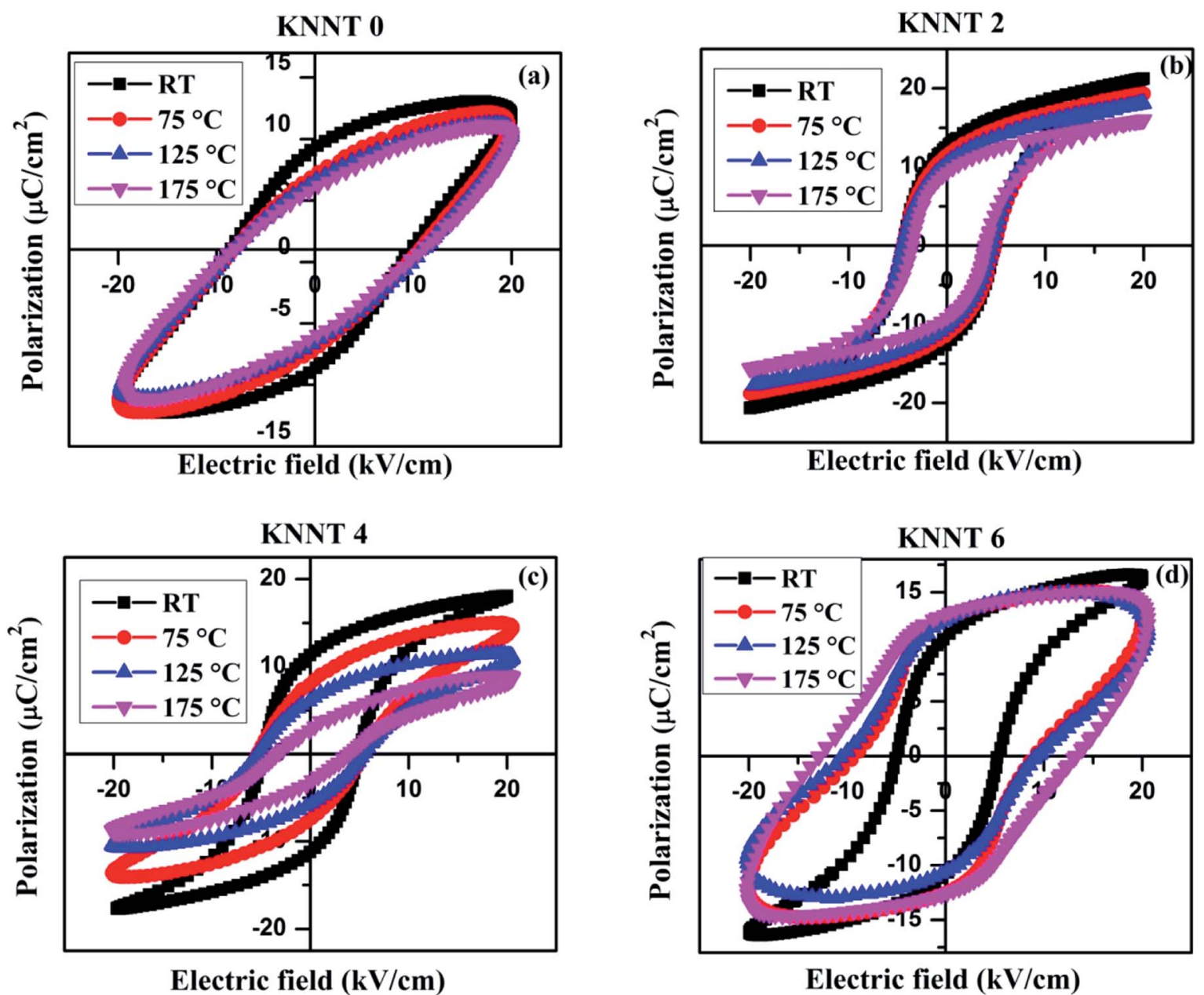

Fig. 6 PE hysteresis loops of (a) KNNTO (b) KNNT2 (c) KNNT4 and (d) KNNT6 samples at various temperatures. 

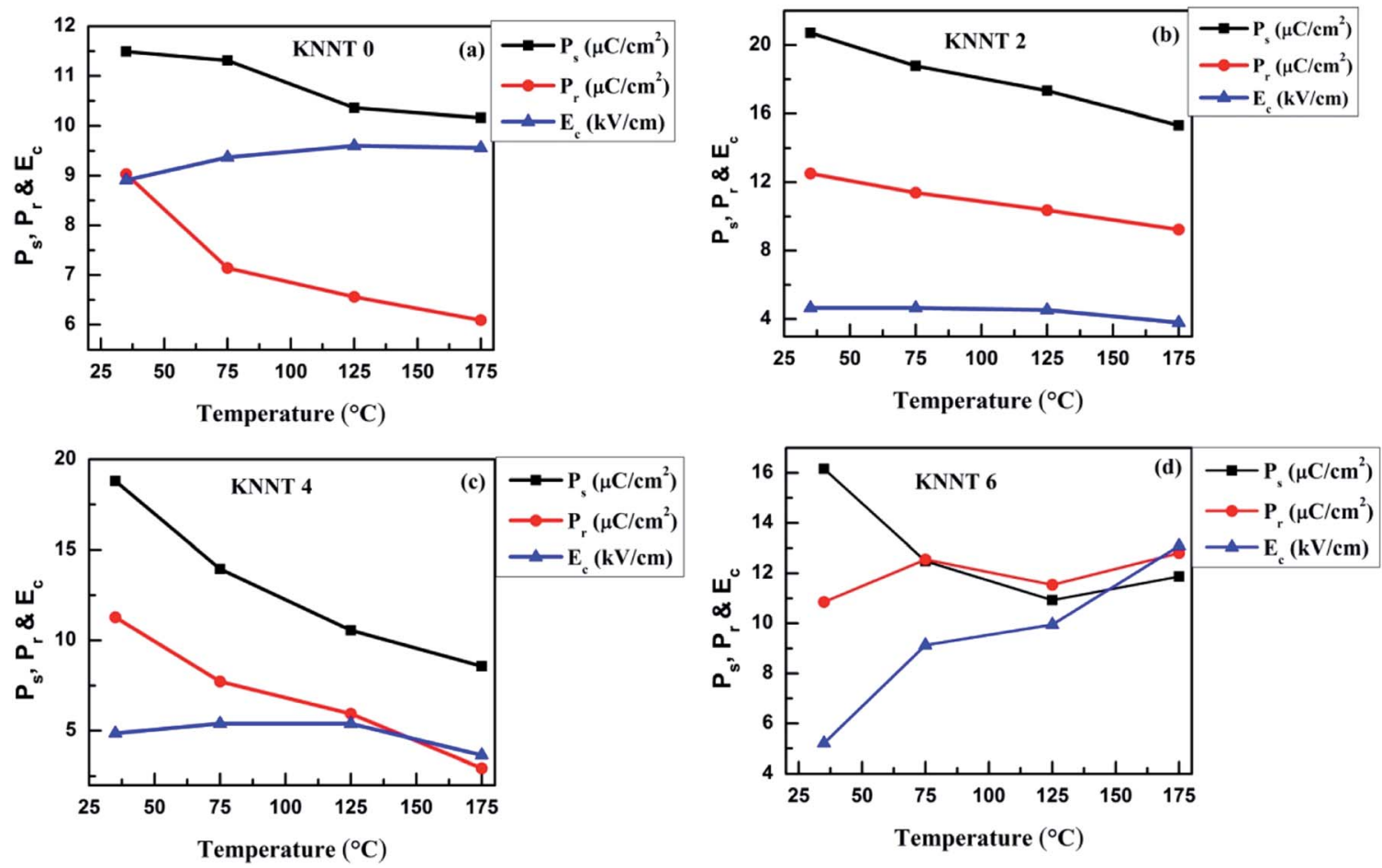

Fig. 7 Diminution in $P_{\mathrm{s}}, P_{\mathrm{r}}$ and $E_{\mathrm{c}}$ with temperature for (a) KNNT (b) KNNT2 (c) KNNT4 and (d) KNNT6 samples at various temperatures.

KNNT6 samples show an increase in $P_{\mathrm{r}}$ by $18 \%$ and a colossal increase in $E_{\mathrm{c}}$ of about $150 \%$. On the other hand, KNNT4 samples show unprecedented decrease in $P_{\mathrm{r}}$ and $P_{\mathrm{S}}$ of $74 \%$ and $54.4 \%$. Such high increase in $E_{\mathrm{c}}$ or decrease in $P_{\mathrm{r}}$ and $P_{\mathrm{s}}$ in KNNT6 and KNNT4 may be due to the presence of ZnO as secondary phase, which would hinder their use in practical applications. The saturated polarization loop of $\mathrm{ZnO}$ doped KNNT samples measured at room temperature can be attributed to the higher grain size of ceramic samples. The reorientations of polarizations get enhanced when the nonpolar grain boundary regions decreases with increase in grain size, which results in saturated $P-E$ loop. ${ }^{40}$ However, as the measurement temperature increases, the $\mathrm{ZnO}$ phase which manifests itself in the form of secondary phase at higher concentrations is believed to generate charge defects. These defects inhibit the polarization switching at higher temperature, resulting in a decrease in $P_{\mathrm{r}}$ and/or increase in $E_{\mathrm{c}}$ of the ceramics. ${ }^{41}$ On the other hand the KNNT2 ceramic samples showed a rather different, improved thermal stability. The value

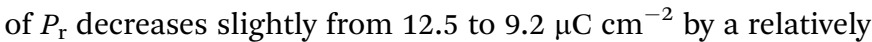
small amount of $26.2 \%$, and the $E_{\mathrm{c}}$ from 4.6 to $3.8 \mathrm{kV} \mathrm{cm}^{-1}$ by $18.5 \%$. Compared to pure, KNNT0 and other relatively higher concentration of ZnO doped KNNT (KNNT4 and KNNT6), the KNNT2 samples have significantly well-sustained polarizations at elevated measurement temperatures.

It is clear that the enhanced ferroelectric and thermal stability properties of KNNT2 are due to the composite structure, where the $\mathrm{Zn}$ ions diffuse into the KNNT matrix compensating for the cation vacancy and thus forming a solid-solution.
Similar behavior have been also observed in the $\mathrm{BNT}^{42}$ and $\mathrm{KNN}^{43}$ based ceramics.

\section{Conclusions}

The role of $\mathrm{ZnO}$ on ferroelectric fatigue and thermal stability of ferroelectric property of lead-free $\left(\mathrm{K}_{0.5} \mathrm{Na}_{0.5}\right)\left(\mathrm{Nb}_{0.7} \mathrm{Ta}_{0.3}\right) \mathrm{O}_{3}$ ceramics prepared by conventional solid state reaction method has been systematically studied and reported. Phase pure KNNT compositions were obtained when an excess amount ( $5 \mathrm{wt} \%$ ) of $\mathrm{K}_{2} \mathrm{CO}_{3}$ was added during the calcination stage. Even though all the compositions were free of secondary phases after calcination, presences of trace amounts of secondary phases were observed after sintering at high temperature for KNNT samples with 4 and $6 \mathrm{wt} \%$ of ZnO. XRD analysis revealed that solubility of $\mathrm{Zn}$ is limited and is less than $2 \mathrm{wt} \%$ of $\mathrm{ZnO}$ in the KNNT matrix. Improved grain size was observed with increase in $\mathrm{ZnO}$ content. The KNNT sample with $2 \mathrm{wt} \% \mathrm{ZnO}$ exhibits enhanced ferroelectric fatigue retention $\left(10^{9}\right.$ cycles $)$ properties. The $P_{\mathrm{r}}$ value was $12.6 \mu \mathrm{C} \mathrm{cm}^{-2}$ for $2 \mathrm{wt} \% \mathrm{ZnO}$ added KNNT which only marginally reduced to 12.5 after $10^{9}$ cycles. In other words, the ferroelectric fatigue of only $0.8 \%$ for $2 \mathrm{wt} \% \mathrm{ZnO}$ added ceramics which were much less compared to $5 \%$ and $30 \%$ fatigue for undoped KNNT and $6 \mathrm{wt} \% \mathrm{ZnO}$ added KNNT samples prepared and measured under identical conditions. Furthermore, the thermal stability of the ferroelectric property has also been strengthened for optimum concentration of $\mathrm{ZnO}$, as can be evidenced from the temperature-dependent $P-E$ measurements. The results suggest that the optimum $\mathrm{ZnO}$ content is $2 \mathrm{wt} \%$ in KNNT matrix which enhances the ferroelectric properties 
making it a potential candidate for application in highly reliable electronic devices.

\section{Conflicts of interest}

There are no conflicts to declare.

\section{Acknowledgements}

The authors acknowledge Department of Physics, Nirmalagiri College, Kannur for providing XRD characterization facilities and Maharajas College, Ernakulam and Avinashilingam University, Coimbatore for SEM facility. VSK acknowledges the facilities provided by CUTN, UGC for the start-up grant and DST-SERB for the Early Career Research grant (ECR/2015/ 000273). VP and RJ acknowledge the facilities and financial support offered by CUTN.

\section{Notes and references}

1 R. E. Cohen, Nature, 1992, 358, 136-138.

2 Y. A. Genenko, et al., Mater. Sci. Eng., B, 2015, 192, 52.

3 X. J. Lou and J. Wang, J. Appl. Phys., 2010, 108, 034104.

4 Q. Zhang and R. W. Whatmore, Mater. Sci. Eng., B, 2004, 109, 136.

5 J. S. Kang and Y. H. Joung, J. Mater. Sci., 2007, 42, 7899.

6 T. Sreesattabud, B. J. Gibbons, A. Watcharapasorn and S. Jiansirisomboon, Ceram. Int., 2013, 39(1), S521-S524.

7 F. Rubio-Marcos, J. J. Romero, M. G. Navarro-Rojero and J. F. Fernandez, J. Eur. Ceram. Soc., 2009, 29, 3045-3052.

8 R. Hayati and A. Barzegar, Mater. Sci. Eng., B, 2010, 172, 121. 9 H. T. Li, et al., Curr. Appl. Phys., 2011, 11, S184.

10 J. Wu, D. Xiao and J. Zhu, Chem. Rev., 2015, 115, 2559.

11 Y. Zhao, et al., J. Am. Ceram. Soc., 2011, 94, 656.

12 H. Takao, et al., J. Am. Ceram. Soc., 2006, 89, 1951.

13 Q. Yin, et al., J. Alloys Compd., 2010, 491, 340.

14 S.-H. Psrk, et al., Jpn. J. Appl. Phys., 2004, 43, L1072.

15 S. L. Yang, et al., J. Am. Ceram. Soc., 2012, 95, 2110.

16 Y. G. Lv, et al., Mater. Res. Bull., 2009, 44, 284.

17 D. Lin, K. W. Kwok and H. L. W. Chan, Appl. Phys. A: Mater.

Sci. Process., 2008, 91, 167.

18 M. Matsubara, et al., J. Am. Ceram. Soc., 2005, 88, 1190.

19 S.-H. Park, et al., Jpn. J. Appl. Phys., 2004, 43, L1072.
20 J. Tellier, B. Malic, B. Dkhil, D. Jenko, J. Cilensek and M. Kosec, Solid State Sci., 2009, 11(2), 320-324.

21 M. A. Rafiq, M. E. V. Costa and P. M. Vilarinho, Sci. Adv. Mater., 2014, 6(3), 426-433.

22 A. Kamal, M. A. Rafiq, M. N. Rafiq, M. Usman, M. Waqar and M. S. Anwar, Appl. Phys. A, 2016, 122, 1037.

23 R. Z. Zuo, J. Rodel, R. Z. Chen and L. T. Li, J. Am. Ceram. Soc., 2006, 89(6), 2010-2015.

24 M. Promsawat, A. Watcharapasorn and S. Jiansirisomboon, Nanoscale Res. Lett., 2012, 7, 65.

25 H. E. Mgbemere, M. Hinterstein and G. A. Schneider, J. Eur. Ceram. Soc., 2012, 32(16), 4341.

26 R. Rani, S. Sharma, R. Rai and A. L. Kholkin, Mater. Res. Bull., 2012, 47(2), 381.

27 Y. Shimojo, R. P. Wang, T. Sekiya and K. Matsuzaki, J. Korean Phys. Soc., 2005, 46(1), 48.

28 L. A. Ramajo, et al., Mater. Res., 2014, 17, 728.

29 K. Imai, et al., J. Cryst. Growth, 1997, 177, 79.

30 A. Sawalha, M. Abu-Abdeen and A. Sedky, Phys. B, 2009, 404, 1316-1320.

31 J. F. Scott, Ferroelectric Memories, Springer, New York, 2000.

32 A. K. Tagantsev, I. Stolichnov, E. L. Colla and N. Setter, J. Appl. Phys., 2001, 90, 1387-1402.

33 X. J. Lou, J. Appl. Phys., 2009, 105, 024101.

34 Z. X. Cheng, X. L. Wang and S. X. Dou, Appl. Phys. Lett., 2007, 90(1-3), 222902.

35 L. Liu, H. Fan, L. Fang, X. Chen, H. Dammak and M. Pham Thi, Mater. Chem. Phys., 2009, 117, 138-141.

36 B. Tah, S. Goswami, T. Dasgupta, J. Bera, P. Sinha, D. Kundu, S. Sen and A. Sen, Ferroelectrics, 2015, 481, 119-125.

37 F. Scott, J. Phys. Chem. Solids, 1996, 57, 1439-1443.

38 L. Jin, F. Li and S. Zhang, J. Am. Ceram. Soc., 2014, 97(1), 127.

39 M. Ehmke, J. Glaum, W. Jo, T. Granzow, J. RödelEhmke, et al., J. Am. Ceram. Soc., 2011, 94, 2473.

40 G. H. Haertling, J. Am. Ceram. Soc., 1999, 82, 797-818.

41 K. Okazaki and K. Nagata, J. Am. Ceram. Soc., 1973, 56, 82-86. 42 J. Zhang, Z. Pan, F. F. Guo, W. C. Liu, H. P. Ning, Y. B. Chen, M. H. Lu, B. Yang, J. Chen, S. T. Zhang, X. R. Xing, J. Rödel, W. Cao and Y. F. Chen, Nat. Commun., 2015, 6, 6615.

43 Z. Pan, J. Chen, L. Fan, J. Zhang, S. Zhang, Y. Huang, L. Liu, L. Fang and X. Xing, J. Am. Ceram. Soc., 2015, 98(12), 39353941. 